\title{
Relationship of body mass index to sleep duration, and current smoking among medical students in Tabuk City, Saudi Arabia
}

Faisal Dahi Aldahash ${ }^{1}$, Saeed Awadh Alasmari ${ }^{1}$, Shelian Juweed Alnomsi ${ }^{1}$, Abdulmajeed Mohammed Alshehri ${ }^{1}$, Nawaf Faisal Alharthi ${ }^{1}$, Ahmad Ali Hassan Aloufi ${ }^{1}$, Meshal Salem Al Atawi ${ }^{1}$, Areej Abdulrhman Alotaibi ${ }^{1}$, Hyder Osman Mirghani ${ }^{2}$

${ }^{1}$ Medical Student, Faculty of Medicine, University of Tabuk, Tabuk, Kingdom of Saudi Arabia

${ }^{2} \mathrm{MD}$, Associate Professor, Department of Medicine, Faculty of Medicine, University of Tabuk, Tabuk, Kingdom of Saudi Arabia

\section{Type of article: Short report}

\begin{abstract}
Background: Being overweight is associated with cardiometabolic risk, and lifestyles including smoking and good sleep hygiene are also implicated. We aimed to assess the dietary habit, time spent on social media, and sleep duration relationship to body mass index (BMI) among medical students in Tabuk, Saudi Arabia.

Methods: A cross-sectional study was conducted among 147 clinical phase medical students in the Medical College, University of Tabuk (Saudi Arabia) from January 2018 to May 2018. A checklist questionnaire was used to measure variables such as age, sex, smoking, level of exercise, whether taking meals and snacks regularly, eating fast food, fruit and vegetable consumption, sleep duration, time spent on social media, and breakfast skipping. Data were analyzed by IBM-SPSS version 20, using one-way ANOVA and Pearson's productionmoment correlation (r). A p-value of less than 0.05 was considered statistically significant.

Results: Participants consisted of $51 \%$ males, mean age (Mean \pm SD) was $22.90 \pm 1.27$ years, sleep duration was $7.50 \pm 2.17$ hours, time spent on social media was $5.54 \pm 3.49$ hours, body mass index was $24.8 \pm 5.19$, and breakfast skipping, fast food consumption, smoking, and regular exercise were reported in $52.4 \%, 87.7 \%, 12.9 \%$, and $36.1 \%$ respectively. A significant negative correlation was evident between BMI and sleep duration $(\mathrm{r}=-0.185$, $\mathrm{p}=0.025)$, cigarette smokers were more likely to be obese compared to their counterparts $(27.28 \pm 6.85$ vs. 24.10 $\pm 4.98, \mathrm{p}=0.018$ ). No significant statistical relationship was evident between BMI, breakfast skipping, fast food, fruit and vegetable intake, and time spent on social media.

Conclusion: BMI was higher among smokers and those with shorter sleep duration, there was no association between BMI and other students' characteristics. Measures to smoking quitting and good sleep hygiene are recommended.

Keywords: Obesity, Sleep duration, Social media, Dietary habits, Medical students
\end{abstract}

\section{Introduction}

Epidemiological studies suggest decreases and breaks of obesity, however, this major health problem is increasing (1). Once considered a problem in high-income countries with the dramatic increase in urban areas, obesity is on the rise worldwide. The prevalence ranges from $20.5 \%$ to $34.7 \%$ in the USA depending on the region and whether selfreported or using objective measures (2-4). Despite substantial clinical and policy targeting obesity, there is no evidence in any age group that the prevalence of obesity is declining, furthermore $17.4 \%$ of children met the criteria for type 1 obesity (5). In the Kingdom of Saudi Arabia, the prevalence is $28.7 \%$ (35.5\% of women and $24.1 \%$ of men) over 15 years of age (6). A study published in Saudi Arabia estimated the prevalence in one region of the

\section{Corresponding author:}

Faisal Dahi Aldahash, Faculty of Medicine, University of Tabuk, PO Box 3378, Tabuk 51941, Saudi Arabia.

Tel: +966.507405784, E-mail: Fa-99-99@hotmail.com

Received: June 06, 2018, Accepted: July 14, 2018, Published: September 2018

iThenticate screening: June 25, 2018, English editing: August 14, 2018, Quality control: August 15, 2018

This article has been reviewed / commented by three experts

Ethics approval: Medical College, University of Tabuk (Ref: 30-305)

(C) 2018 The Authors. This is an open access article under the terms of the Creative Commons Attribution-NonCommercialNoDerivs License, which permits use and distribution in any medium, provided the original work is properly cited, the use is non-commercial and no modifications or adaptations are made. 
Kingdom to be $63.4 \%$, with near three-quarters of females being obese, necessitating urgent measures to be undertaken (7). Obesity is a risk factor for severe diseases like diabetes mellitus, hypertension, dyslipidemias, and obstructive sleep apnea causing a lot of morbidity and mortality and putting high pressure on health resources $(8$ 10). Chronic sleep curtailment has been associated with increased overall and central adiposity and cardiovascular risk factors among children and adolescents (11). Previous studies have documented associations between sleep duration, sleep quality, and obesity risk in older individuals (12-14). Sedentary lifestyle and unhealthy diet are associated with obesity and diabetes mellitus, the adoption of moderate physical activity and a health-friendly diet are essential, achievable, preventive measures for obesity and type 2 diabetes and the maintenance of both physical and mental health $(15,16)$. Medical students are an important sector of the community; they are the doctors of the near future and will be the health educators. Their lifestyles in regard to eating behavior, physical activity, and sleep duration are rarely evaluated. Literature regarding this important topic is lacking. To our best of knowledge, this is the first study to assess sleep duration, the social media, physical activity, and dietary habits among medical students in Tabuk City and relating them to body mass index. Investigating obesity and its associated risk factors could help in preventing this common morbid disease by implementing the necessary interventions. Thus, we proposed this research to study breakfast skipping, fast food, fruit and vegetable consumption, and sleep duration with relationship to body mass index among medical students in Tabuk, Kingdom of Saudi Arabia.

\section{Material and Methods}

\subsection{Research design and participants}

This cross-sectional study was conducted among the clinical stage medical students of Medical College, University of Tabuk (Saudi Arabia) from January 2018 to May 2018. The University of Tabuk lies in north-west Saudi Arabia with four Colleges and 5,000 students.

\subsection{Sampling}

The participants were randomly selected from the class list $\left(4^{\text {th }}, 5^{\text {th }}\right.$, and $6^{\text {th }}$ classes $)$, and then two out of three students from the serial number were chosen (total 210 students). Students were approached in a ratio of 2:1 from the class list (two students were chosen from three) to select 147 participants.

\subsection{Ethical consideration}

The ethics of study was approved by the ethics committee of Medical College, University of Tabuk (Ref: 30-305). A meeting was prepared with the participants and they were informed that their participation was completely voluntary and their information would be considered confidential. The participants read a one-page information sheet about the study and signed a written informed consent, then completed the checklist. Also, the students were assured that their marks or teaching would not be affected by any means.

\subsection{Data collection}

The following information was collected: Age, sex, class, smoking, level of exercise (assessed by if involved in moderate physical activity for 30 minutes/day) if taking meals and snacks regularly, fast food, fruit and vegetable consumption (assessed by answering two questions: how many times/week do you take the following food items? and how many servings/day?), sleep duration, time spent on social media, and breakfast skipping. The weight and height of all the participants were measured, and the body mass index was calculated. Breakfast was defined as any food or beverages consumed between 5:00 a.m. and 10:00 a.m. (17), those who skipped breakfast for at least three days were defined as breakfast skippers.

\subsection{Statistical analysis}

The Statistical Package for Social Sciences (SPSS) IBMC SPSS@ version 20 (IBM@ Corp, Armonk, NY, USA) was used for data analysis. The one-way ANOVA and Pearson product-moment correlation were used to test the relation between body mass index and different parameters. A P-value of $<0.05$ was considered significant.

\section{Results}

Out of 147 clinical phase medical students (51\% males), 34.7\% were 4 th class, 32.7\% were 5 th class, while $32.7 \%$ were 6 th class, $17.7 \%$ were overweight, and $12.9 \%$ were obese. The current data showed that only $36.1 \%$ were practicing regular exercise, $12.9 \%$ were smokers, $66.7 \%$ were taking their meals regularly, 63.9\% were taking regular snacks, breakfast skipping was reported in $52.4 \%$, the majority were consuming fast food regularly, and $53.7 \%$ were regular consumers of fruits and vegetables (Table 1). In the current study, the mean height was $162.93 \pm 8.21 \mathrm{~cm}$, the mean weight was $65.43 \mathrm{~kg}$, mean body mass index (BMI) was $24.8 \pm 5.19 \mathrm{~kg} / \mathrm{m}^{2}$, sleep duration 
was $7.50 \pm 2.17$ hours, and the time spent on social media was $5.54 \pm 3.49$ hours. In the current study, a significant negative correlation was found between sleep duration and body mass index (Pearson correlation coefficient $(\mathrm{r})=$ $0.185, p=0.025$ ), while no significant correlation was reported between body mass index and time spent on social media ( $\mathrm{r}=-0.158, \mathrm{p}=0.055)$ (Table 2). In the present study, a significant statistical difference (one-way ANOVA) was evident between cigarette smokers and their counterparts regarding BMI (27.28 \pm 6.85 vs. 24.10 $\pm 4.98, p=0.018)$, no significant differences were found between breakfast skippers and regular consumers $(24.23 \pm 5.58$ vs. $23.92 \pm 4.76, \mathrm{p}=0.175)$, and exercise $(24.43 \pm 5.51$ vs. $23.68 \pm 4.80, \mathrm{p}=0.384)$. Table 3 illustrates the relationship of body mass index and dietary habit of the medical students.

Table 1. Dietary habits, body mass index, sex, smoking, and exercise among the study group

\begin{tabular}{|l|l|l|}
\hline \multicolumn{2}{|l|}{ Character } & Correct answer; n (\%) \\
\hline \multirow{3}{*}{ Sex } & Males & $75(51)$ \\
\cline { 2 - 3 } & Females & $50(49)$ \\
\hline \multirow{3}{*}{ Class } & $6^{\text {th }}$ & $48(32.7)$ \\
\cline { 2 - 3 } & $5^{\text {th }}$ & $48(32.7)$ \\
\cline { 2 - 3 } & $4^{\text {th }}$ & $51(34.7)$ \\
\hline \multirow{3}{*}{ BMI } & Obese & $26(17.7)$ \\
\cline { 2 - 3 } & Overweight & $19(12.9)$ \\
\hline Exercise & $53(36.1)$ \\
\hline Smoking & $19(12.9)$ \\
\hline Taking meals regularly & $98(66.7)$ \\
\hline Taking snacks & $94(63.9)$ \\
\hline Breakfast skipping & $77(52.4)$ \\
\hline Fast food & $129(87.7)$ \\
\hline Fruits and vegetables & $79(53.7)$ \\
\hline
\end{tabular}

Table 2. Correlation between body mass indexes, time spent on social media, and sleep duration

\begin{tabular}{|l|l|l|}
\hline Character & Correlation coefficient $(\mathrm{r})^{*}$ & $\mathrm{p}$-value \\
\hline Social media & -0.158 & 0.055 \\
\hline Sleep duration & -0.185 & 0.025 \\
\hline
\end{tabular}

* Pearson product-moment correlation test

Table 3. The relation to body mass index, breakfast skipping, fast food, and fruit and vegetable intake, smoking, and exercise

\begin{tabular}{|l|l|l|l|}
\hline Character & BMI $\left(\mathrm{kg} / \mathrm{m}^{2}\right)$ & p-value* \\
\hline Breakfast behavior & Breakfast skippers & $24.23 \pm 5.58$ & 0.715 \\
\cline { 2 - 3 } & Non-skippers & $23.92 \pm 4.76$ & \\
\hline Fruits and vegetable intake & Regular intake & $24.63 \pm 5.67$ & 0.172 \\
\cline { 2 - 3 } & Irregular intake & $23.45 \pm 4.53$ & \\
\hline \multirow{2}{*}{ Exercise } & Regular exercise & $24.43 \pm 5.51$ & 0.384 \\
\cline { 2 - 3 } & Irregular exercise & $23.68 \pm 4.80$ & \\
\hline \multirow{2}{*}{ Smoking } & Smokers & $27.28 \pm 6.85$ & \multirow{2}{*}{0.018} \\
\cline { 2 - 3 } & Non-smokers & $24.10 \pm 4.98$ & \\
\hline Fast food intake & Yes & $24.19 \pm 5.24$ & 0.501 \\
\cline { 2 - 3 } & No & $23.31 \pm 4.91$ & \\
\hline
\end{tabular}

* Pearson product-moment correlation test

\section{Discussion}

The current study, showed obesity in (17.7\%) and overweight (12.9\%), the current data were similar to a study published in China (18) and reported similar findings. In the present study, a significant correlation was found between sleep duration and BMI, and those who were cigarette smokers were more likely to be obese than their counterparts. The association of sleep duration with obesity is in line with the study of Khemayanto et al. (13) who found similar results. In similarity to the present findings are Cao et al., (19) who reported the association of short sleep duration and obesity and that increasing the awareness of the students regarding good sleep hygiene is highly 
recommended. A recent study published in Nepal (20) found that cigarette smokers were more obese compared to non-smokers, which is in line with the current findings in which smokers had a higher body mass index. An urgent interventional program addressing the association of smoking and obesity and their cardiovascular risk is highly needed. The reported smoking rate in the current study was lower than a percentage $(24.8 \%)$ reported among students in Hungary (21) and higher than a study from China (22). In the present study, breakfast skipping is congruent with the findings of Sun et al. (23) who reported a prevalence of $41.7 \%$. No association was found between breakfast skipping and body mass index, in accordance with a study conducted in Poland (24), and concluded similar results. The current data showed an association between fruit and vegetable consumption and body mass index, whereas a previous study (25) found no association between fresh fruits and vegetables and obesity, supporting the current observation. A study conducted among medical students in British Colombia (26) concluded that $64 \%$ of the students met the recommendation for physical activity. More effort is needed regarding the implementation of an exercise program in our college, as only $36.1 \%$ were practicing exercise.

Eating fast food is associated with high energy consumption and vitamin deficiency. In the present study, $87.7 \%$ of students consumed fast food at least four times/day and the consumers were not more obese than their counterparts. A previous study (27) found that $84.1 \%$ of students consumed fast food regardless of their nutritional status and in accordance with the current observation. The previous study (27) reported no significant differences in BMI between fast food consumers and those who did not consume the food, which is in line with the current data. The present data showed no correlation between body mass index and the time spent on social media. Similarly, a study published in Iran (28) assessed the home environment and found that sleep duration was the only behavior associated with weight status. A plausible explanation could be the time of social media and not merely the duration, as using social media at night is associated with poor sleep quality, depression, and anxiety (29).

\section{Study limitations and strength}

The strength of the present study is that we assessed various lifestyles including smoking, sleep duration, and dietary habits, which can be easily addressed as preventive measures for obesity. The study limitations were the small size of the study sample, the reliance on a self-administered questionnaire, which is more prone to subjectivity, and that the study was conducted at a single college, so the result cannot be generalized to the Kingdom of Saudi Arabia. A major limitation is that we did not use polysomnography - a multi-parametric test used in the study of sleep and as a diagnostic tool in sleep medicine.

\section{Conclusions}

A significant negative correlation was found between body mass index and sleep duration, those who were current smokers were more likely to be obese than non-smokers. There was no significant difference between breakfast skippers, fruit and vegetable, and fast food consumers, and those who spent more time on social media and their counterparts regarding body mass index. Increasing the awareness of medical students about good sleep, hygiene and smoking cessation is highly recommend. Further, larger multi-center studies focusing on meal timing, sleep quality, and central adiposity are needed.

\section{Acknowledgments:}

We would like to acknowledge Dr. Yassin Ibrahim (Assistant Professor of Community Medicine, Medical College, and University of Tabuk) for the statistical analysis.

\section{Conflict of Interest:}

There is no conflict of interest to be declared.

Authors' contributions:

All authors contributed to this project and article equally. All authors read and approved the final manuscript.

\section{References:}

1) Visscher TL, Heitmann BL, Rissanen A, Lahti-Koski M, Lissner L. A break in the obesity epidemic? Explained by biases or misinterpretation of the data? Int J Obes (Lond). 2015; 39(2): 189-98. doi: 10.1038/ijo.2014.98. PMID: 24909829.

2) Centers for Disease Control and Prevention, Overweight, and Obesity. 2013. Available from: http://www.cdc.gov/obesity/data/adult.html. 
3) Ng M, Fleming T, Robinson M, Thomson B, Graetz N, Margono C, et al. Global, regional, and national prevalence of overweight and obesity in children and adults during 1980-2013: A systematic analysis for the Global Burden of Disease Study 2013. The Lancet. 2014; 384(9945): 766-81. doi: 10.1016/S01406736(14)60460-8.

4) Flegal KM, Carroll MD, Kit BK, Ogden CL. Prevalence of obesity and trends in the distribution of body mass index among US adults, 1999-2010. JAMA. 2012; 307(5): 491-7. doi: 10.1001/jama.2012.39. PMID: 22253363.

5) Skinner AC, Perrin EM, Skelton JA. Prevalence of obesity and severe obesity in US children, 1999-2014. Obesity (Silver Spring). 2016; 24(5): 1116-23. doi: 10.1002/oby.21497. PMID: 27112068.

6) Memish ZA, El Bcheraoui C, Tuffaha M, Robinson M, Daoud F, Jaber S, et al. Obesity and Associated Factors - Kingdom of Saudi Arabia, 2013. Prev Chronic Dis. 2014; 11: E174. doi: 10.5888/pcd11.140236. PMID: 25299980, PMCID: PMC4193060.

7) Ahmed HG, Ginawi IA, Elasbali AM, Ashankyty IM, Al-Hazimi AM. Prevalence of obesity in Hail region, KSA: in a comprehensive survey. J Obes. 2014; 2014: 961861. doi: 10.1155/2014/961861.

8) Haslam DW, James WP. Obesity. Lancet. 2005; 366(9492): 1197-209. doi: 10.1016/S01406736(05)67483-1.

9) Kelsey MM, Zaepfel A, Bjornstad P, Nadeau KJ. Age-related consequences of childhood obesity. Gerontology. 2014; 60(3): 222-8. doi: 10.1159/000356023. PMID: 24434909.

10) Withrow $D$, Alter DA. The economic burden of obesity worldwide: a systematic review of the direct costs of obesity. Obes Rev. 2011; 12(2): 131-41. doi: 10.1111/j.1467-789X.2009.00712.x. PMID: 20122135.

11) Taveras EM, Gillman MW, Peña MM, Redline S, Rifas-Shiman SL. Chronic sleep curtailment and adiposity. Pediatrics. 2014; 133(6): 1013-22. doi: 10.1542/peds.2013-3065.

12) Gildner TE, Liebert MA, Kowal P, Chatterji S, Josh Snodgrass J. Sleep duration, sleep quality, and obesity risk among older adults from six middle-income countries: findings from the study on global AGEing and adult health (SAGE). Am J Hum Biol. 2014; 26(6): 803-12. doi: 10.1002/ajhb.22603. PMID: 25130760.

13) Khemayanto H, Shi B. Role of Mediterranean diet in prevention and management of type 2 diabetes. Chin Med J (Engl). 2014; 127(20): 3651-6. PMID: 25316244.

14) Kim CE, Shin S, Lee HW, Lim J, Lee JK, Shin A, Kang D. Association between sleep duration and metabolic syndrome: a cross-sectional study. BMC Public Health. 2018; 18(1): 720. doi: 10.1186/s12889018-5557-8.

15) Rahe C, Czira ME, Teismann H, Berger K. Associations between poor sleep quality and different measures of obesity. Sleep Med. 2015; 16(10): 1225-8. doi: 10.1016/j.sleep.2015.05.023. PMID: 26429750.

16) Kopp M, Steinlechner M, Ruedl G, Ledochowski L, Rumpold G, Taylor AH. Acute effects of brisk walking on affect and psychological well-being in individuals with type 2 diabetes. Diabetes Res Clin Pract. 2012; 95(1): 25-9. doi: 10.1016/j.diabres.2011.09.017. PMID: 21995867.

17) Nakajima K, Suwa K. Association of hyperglycemia in a general Japanese population with late-nightdinner eating alone, but not breakfast skipping alone. J Diabetes Metab Disord. 2015; 14: 16. doi: 10.1186/s40200-015-0147-0. PMID: 25874189, PMCID: PMC4396539.

18) Appelhans BM, Fitzpatrick SL, Li H, Cail V, Waring ME, Schneider KL, et al. The home environment and childhood obesity in low-income households: indirect effects via sleep duration and screen time. BMC Public Health. 2014; 14: 1160. doi: 10.1186/1471-2458-14-1160.

19) Cao M, Zhu Y, He B, Yang W, Chen Y, Ma J, et al. Association between sleep duration and obesity is ageand gender-dependent in Chinese urban children aged 6-18 years: a cross-sectional study. BMC Public Health. 2015; 15: 1029. doi: 10.1186/s12889-015-2359-0. PMID: 26446623, PMCID: PMC4596376.

20) Nepal G, Tuladhar ET, Dahal S, Ahamad ST, Adhikari S, Kandel A. Lifestyle Practices and Obesity in Nepalese Youth: A Cross-sectional Study. Cureus. 2018; 10(2): e2209. doi: 10.7759/cureus.2209. PMID: 29686951 PMCID: PMC5910009.

21) Pénzes M, Czeglédi E, Balázs P, Foley KL. Factors associated with tobacco smoking and the belief about weight control effect of smoking among Hungarian adolescents. Cent Eur J Public Health. 2012; 20(1): 11 7. PMID: 22571010 , PMCID: PMC3821967.

22) Park SE, Yun SN, Cui W, Kim H. Smoking in korean-chinese middle school students: prevalence and risk factors. J Nurs Res. 2013; 21(2): 139-47. doi: 10.1097/jnr.0b013e3182921f35.

23) Sun J, Yi H, Liu Z, Wu Y, Bian J, Wu Y, et al. Factors associated with skipping breakfast among Inner Mongolia medical students in China. BMC Public Health. 2013; 13: 42. doi: 10.1186/1471-2458-13-42. 
24) Kanikowska D, Sikorska D, Kuczyńska B, Grzymisławski M, Bręborowicz A, Witowski J. Do medical students adhere to advice regarding a healthy lifestyle? A pilot study of BMI and some aspects of lifestyle in medical students in Poland. Adv Clin Exp Med. 2017; 26(9): 1391-8. doi: 10.17219/acem/65783.

25) Zhang J, Jin X, Yan C, Jiang F, Shen X, Li S. Short sleep duration as a risk factor for childhood overweight/obesity: a large multicentric epidemiologic study in China. Sleep Health. 2015; 1(3): 184-90. doi: 10.1016/j.sleh.2015.06.001. PMID: 29073439.

26) Holtz KA, Kokotilo KJ, Fitzgerald BE, Frank E. Exercise behaviour and attitudes among fourth-year medical students at the University of British Columbia. An Fam Physician. 2013; 59(1): e26-32.

27) Zalewska M, Maciorkowska E. Selected nutritional habits of teenagers associated with overweight and obesity. Peer J. 2017; 5: e3681. doi: 10.7717/peerj.3681. PMID: 28951812, PMCID: PMC5611898.

28) Payab M, Kelishadi R, Qorbani M, Esmaeil Motlagh M, Hasani-Ranjbar S, Ejtahed HS, et al. Association of healthy foods intake with anthropometric measures and blood pressure in a national sample of Iranian children and adolescents: the CASPIAN- IV study. Minerva Pediatr. 2016. PMID: 26899670.

29) Woods HC, Scott H. \#Sleepyteens: Social media use in adolescence is associated with poor sleep quality, anxiety, depression and low self-esteem. J Adolesc. 2016; 51: 41-9. doi: 10.1016/j.adolescence.2016.05.008. PMID: 27294324. 